\title{
Spatial Filtering Technique as Powerful Tool for Real-Time Particle Size Measurement for Fluid Bed Applications in Pharmaceutical Industry
}

\author{
S. Dietrich ${ }^{1}, \underline{\text { D. PetraK }}{ }^{2}$, M. KöHLER ${ }^{1}$, G. ECKARdT ${ }^{1}$ \\ ${ }^{1}$ Parsum GmbH, Chemnitz, Germany \\ ${ }^{2}$ Chemnitz University of Technology, Chemnitz, Germany \\ E-mail: petrak@imech.tu-chemnitz.de (D. Petrak)
}

Sci Pharm. 2010; 78: 586

doi:10.3797/scipharm.cespt.8.LPPT06

The control of particulate processes and their understanding can be improved by modern measuring techniques. The paper describes the optical probe system Parsum IPP 70 as an example of the modern measuring techniques which is based on the spatial filtering technique (SFT). Measuring principles are the fibre-optical spatial filtering velocimetry and the fibre-optical spot scanning in order to determine simultaneously the size and the velocity of particles. Therefore the measured particle size distributions are chord length distributions which can be recalculated. A calibration is not necessary.

The Parsum IPP 70 is a compact and highly robust measuring system for application as an in-line particle size analyzer for processes involving larger particulate sizes up to $6000 \mu \mathrm{m}$. It allows a data rate up to 20,000 particles per second and the system can track continuously a large variety of process parameters. Different options of the measuring system are available: tube length up to $4 \mathrm{~m}$, air supply system for dispersion and cleaning, comprehensive software support, Ex-Zones and pharma solutions.

The application is given for grinding/dosing, agglomeration, fluidized bed processes, mixing and coating, sieving, wet and dry granulation, spray drying. The Parsum IPP 70 is a powerful tool for process control of fluid bed granulation in pharmaceutical industry. The advantages are: increase of process transparency, short response time in the event of process disturbances, continuous control of product quality, full feedback control for automated solutions, no need of samples and laboratory analysis. Results are given by Petrak et al. [1]. Examples show also the ability to prove the model goodness of a fluid bed process by using IPP 70 in-line-SFT [2-4].

[1] Petrak D, Dietrich S, Eckardt G, Köhler M. In-line particle sizing for process control by an optical probe based on the spatial filtering technique (SFT). Proceedings CD World Congress on Particle Technology 2010; Nürnberg. Germany.

[2] Schmidt-Lehr S, Moritz H-U, Jürgens KC. Online Control of Particle Size during Fluidised Bed Granulation. Pharm Ind. 2007; 69: 478-484.

[3] Närvänen T, Lipsanen T, Antikainen O, Räikkönen H, Yliruusi J. Controlling granule size by granulation liquid feed pulsing. Int J Pharm. 2008; 357: 132-138. doi:10.1016/j.ijpharm.2008.01.060

[4] Närvänen T. Particle Size Determination during Fluid Bed Granulation 2009; Diss. Faculty of Pharmacy of the University of Helsinki. 